\title{
Clinical, surgical and histopathological characteristics of liver transplant recipients: An analysis of a large sample from Turkey
}

\author{
(1) Atilla Bulur ${ }^{1}$, (1) Murat Sevmiş ${ }^{2}$
}

${ }^{1}$ Nazilli State Hospital, Clinic of Gastroenterology, Aydin, Turkey

2Istanbul Yeni Yuzyil University Faculty of Medicine, Gaziosmanpasa Hospital, Clinic of General Surgery and Transplantation, Istanbul, Turkey

\section{Date submitted: \\ 19.03.2021}

\section{Date accepted:}

12.04.2021

Online publication date:

15.03.2022

\section{Corresponding Author:}

Atilla Bulur, M.D., Nazilli State

Hospital, Clinic of Gastroenterology,

Aydin, Turkey

atillabulur@hotmail.com

ORCID:

orcid.org/0000-0001-8089-7740

Keywords: Liver transplantation, clinical, surgical, histopathological

\begin{abstract}
Aims: Liver transplantation (LT) is the most effective treatment method for end-stage liver failure and acute liver failure, depending on all causes. This study aimed to examine the clinical, surgical, and histopathological characteristics of LT recipients in a referral center in Turkey.

Methods: In this single-center study, demographic, clinical, laboratory, radiological, surgical, and histopathological data of LT recipients aged 18 years or over between December 2017 and February 2021 were retrospectively analyzed. All subjects were transplanted from live donors and cadavers.
\end{abstract}

Results: The sample included 162 subjects [mean age: 50.1 (18-70) years; male: $64.8 \%$. The proportion of live donor transplantation was $86.4 \%(n=140)]$. The mean follow-up time was 20.5 months (1-39 months). The most common primary indication was hepatocellular carcinoma $(n=43,26.5 \%)$ and chronic hepatitis B virus infection-related cirrhosis $(n=30,18.5 \%)$. The most common postoperative complication was biliary complications (30.9\%). One-year survival was $88.9 \%$, two-year survival was $85.8 \%$, and three-year survival was $83.3 \%$. During the 3 -year follow-up, the total graft loss rate was observed by $17.9 \%$, and the mortality rate was $15.4 \%$.

Conclusions: The main goal in LT is the long-term survival of the graft and the patient. The present study showed that demographic characteristics, etiological characteristics, postoperative complications, and mortality rates among LT recipients were consistent with the results of other centers around the world.

\section{Introduction}

Liver transplantation (LT) was performed first in 1963 in the United States by Thomas Starzl. Today, LT is the most effective treatment for end-stage liver failure and acute liver failure (ALF) (1). LT has been performed on more than 80000 patients with chronic liver failure in the world (2). Recently, survival rates after transplantation have increased considerably, with $96 \%$ in 1 year and $71 \%$ in 10 years after transplantation (3). The underlying reasons for this success are the introduction of new immunosuppressive agents, advances in surgical techniques, early diagnosis and treatment of complications after LT (4).
Generally, the most common LT indication is cirrhosis with end-stage liver failure, followed by hepatocellular carcinoma (HCC) and acute ALF (2). The most common indications of LT in Europe between 1988 and 2011 were reported as cirrhosis (57\%), cancer $(15 \%)$, cholestatic diseases $(10 \%)$, ALF $(8 \%)$, metabolic disease (6\%) and other causes including Budd-Chiari syndrome, benign liver tumors, polycystic diseases, parasitic diseases (4). ALF requires immediate LT, and the most common underlying diseases are viruses (most commonly hepatitis $A$ and $B$ viruses), drugs (most commonly acetaminophen), and toxic agents (2). The priority of patients on the waiting list is determined by the Child (child turcotte pugh) score and, since 
2002, the model of end-stage liver disease (MELD) scoring system (2). Patients with end-stage liver failure with a MELD score of 15 and above are recommended to be included in the transplantation list, while the risk of death of patients with a score above 30 and the risk of morbidity and mortality that will increase after transplantation should be taken into consideration $(5,6)$.

In addition to numerous advances in surgical techniques, recipient selection and donor management, organ preservation, perioperative anesthesia, advances in postoperative care and effective immunosuppressive treatments increase long-term survival success after transplantation (7). The immunosuppressive treatment regimen typically consists of a calcineurin inhibitor (cyclosporine or tacrolimus), an antimetabolite (azathioprine or mycophenolate), corticosteroids, sirolimus, and everolimus (8,9). Despite the effective immunosuppressive treatment and advances in surgical techniques in LT, postoperative complications are still an important issue. Infections, acute rejections, vascular and biliary tract pathologies continue to be the most important complications in the early postoperative period $(10,11)$. Development of de novo malignancies, new cardiovascular events, and recurrence of primary disease are important causes of long-term graft loss and mortality $(12,13)$.

The characteristics of LT recipients in Turkey have been reported in relatively small samples, and mostly from nonreferral centers. Therefore, the current study aimed to examine the clinical, surgical, and histopathological findings of donor and cadaver-derived LT.

\section{Methods}

This was a single-center, retrospective study that included LT recipients who underwent surgery at Istanbul Yeni Yuzyil University, Faculty of Medicine, Gaziosmanpasa Hospital, department of general surgery and transplantation clinic between December 2017 and February 2021. Included patients were adults over the age of 18 who underwent LT for the first time from live donors or cadavers. Younger patients and those who were admitted for a repeat LT for any cause were excluded. The study protocol was approved by the Clinical Research Ethics Committee of Istanbul Yeni Yuzyil University (protocol date and number: 13.08.2020/033).

Data were obtained using electronic medical records. Age, gender, height, weight, body mass index (BMI), blood type, child score, MELD (model of end-stage liver disease) score (calculated with a mathematical formula via internet application), medical history, and underlying diseases for transplantation indication were determined. The date, timing, and duration of surgery, blood products used, and perioperative complications were recorded. Early postoperative intensive care requirement, need for mechanical ventilation, and length of hospital stay was obtained. Follow-up data at the outpatient clinic that included laboratory, radiological, histopathological (biopsy performed before and after the operation, macroscopic and histopathological examination of hepatectomy materials), medical, and surgical treatments, complications, and mortality were recorded using the patient records.

The same surgery team performed the operations of the patients included in the current study, and the same gastroenterology team performed follow-up.

\section{Statistical Analysis}

The Statistical Package for the Social Sciences Statistics for Windows, version 25 (Armonk, NY: IBM Corp., 2017) and MedCalc statistics package program were used for data evaluation. Descriptive statistics of categorical variables are presented as numbers and percentages. Scale variables are presented as meantstandard deviation for normally distributed variables and as median (minimum-maximum) for non-normally distributed variables.

\section{Results}

The study sample included 162 subjects [mean age: 50.1 (18-70) years; male: $64.8 \%$ ]. The mean age of men and women was 51.8 years and 47.1 years, respectively. The mean height measured before transplantation was $165.6 \mathrm{~cm}$, the mean weight was $73.7 \mathrm{~kg}$, and the mean BMI was 26.9 (Table 1). The blood type groups, Child score, MELD score, and other preoperative findings are summarized in Table 1.

The etiology of the transplantation was chronic Hepatitis $B$ virus (HBV) infection-related cirrhosis in 30 patients (18.5 $\%$ ), cryptogenic liver cirrhosis in 27 patients (16.7\%), geneticmetabolic liver diseases (autoimmune hepatitis, Wilson's disease, primary sclerosing cholangitis, primary biliary cholangitis, hemochromatosis, sickle cell anemia) in 25 patients (15.4\%), cirrhosis linked to non-alcoholic steatohepatitis (NASH) in 21 patients (13.0\%), alcohol-related cirrhosis in 19 patients (11.7\%), and ALF in 5 patients (3.0\%) (Table 2). The number of patients transplanted with the diagnosis of HCC was $43(26.5 \%$ of all transplants), and the most common underlying cause in these patients was chronic HBV infection (Table 3).

Living donor LT and cadaveric LT were performed in $140(86.4 \%)$ and 22 (13.6\%) patients, respectively. Four (9.3\% of all HCC) of HCC patients underwent transarterial chemoembolization, 1 patient $(2.3 \%$ of all HCC) underwent radiofrequency ablation, and 1 patient had liver resection preoperatively. Perioperative and early postoperative evaluation showed a mean operation time of $6 \mathrm{~h}$ and $7 \mathrm{~min}, 4$ units of erythrocyte suspension, 2.5 units of frozen plasma suspension, and 0.3 units of platelet suspension requirement. The number of days of intensive care after the operation was 2.1 days, and the length of hospital stay was 17.3 days. Twenty (12.3\%) needed 
mechanical ventilation in the intensive care unit during a mean of 1.8 days.

The most common perioperatively postoperative surgical complications were bile duct complications [primarily bile leaks and strictures: 22 (13.6\%) and 20 (12.4\%), respectively, and vascular complications: primarily portal vein thrombosis, hepatic artery thrombosis; $6(3.7 \%)$ and $4(2.5 \%)$, respectively]. The most common late complications were intraabdominal bleeding and complications requiring intraabdominal surgery [ileus, colon perforation, duodenal perforation; $1(0.6 \%), 1(0.6 \%), 1(0.6 \%)$, respectively]. Delirium in $11(6.8 \%)$ and epileptic seizures in 3 $(1.9 \%)$ were the other complications.
Following surgery, immunosuppressive treatment was started with corticosteroids, tacrolimus, and mycophenolate mofetil in all patients. Antithymocyte globulin therapy was administered to $3(1.9 \%)$ patients with early signs of acute rejection. Perioperative/early postoperative and postoperative/ late postoperative operational complications are summarized in Table 4.

The mean follow-up period (transplant age) was 20.49 months (1-39 months). Graft loss developed in 29 (17.9\%) patients and mortality occurred in $25(86.2 \%)$ of them. Time to graft loss was 207.9 (1-950) days, and time to mortality time was 195.56 (3-950) days. Two (6.9\%) patients developed chronic

\begin{tabular}{|c|c|c|}
\hline Age, years, mean (min.-max.) & & $50.1(18-70)$ \\
\hline \multirow[t]{2}{*}{ Gender, n (\%) } & Male & $105(64.8)$ \\
\hline & Female & $57(35.2)$ \\
\hline \multirow{2}{*}{ Donor, n (\%) } & Cadaver & $140(86.4)$ \\
\hline & Living & $22(13.6)$ \\
\hline \multirow{3}{*}{ Child classification, n (\%) } & Child A: & $11(7.1 \%)$ \\
\hline & Child B: & $108(70.1 \%)$ \\
\hline & Child C: & $35(22.7 \%)$ \\
\hline MELD score, mean (min.-max.) & & $16.3(8-35)$ \\
\hline Body mass index, mean (min.-max.) & & $26.9(16.5-37.6)$ \\
\hline \multirow{4}{*}{ Blood group, n (\%) } & A & $66(40.7)$ \\
\hline & B & $32(19.8)$ \\
\hline & $A B$ & $17(10.5)$ \\
\hline & $\mathrm{O}$ & $47(29.0)$ \\
\hline
\end{tabular}

\begin{tabular}{|c|c|c|}
\hline \multirow{3}{*}{ Chronic viral hepatitis, n (\%) } & Hepatitis $B$ virus & $30(18.5)$ \\
\hline & Hepatitis D virus & $6(3.7)$ \\
\hline & Hepatitis $C$ virus & $4(2.5)$ \\
\hline \multirow{3}{*}{ Acute liver failure, $n(\%)$} & Toxic hepatitis & $2(1.2)$ \\
\hline & Wilson's disease & $2(1.2)$ \\
\hline & Hepatitis B virus & $1(0.6)$ \\
\hline \multirow{6}{*}{ Genetics-metabolic liver diseases, $n(\%)$} & Autoimmune hepatitis & $10(6.2)$ \\
\hline & Wilson's disease & $7(4.3)$ \\
\hline & Primary sclerosing cholangitis & $4(2.5)$ \\
\hline & Primary biliary cirrhosis & $2(1.2)$ \\
\hline & Hemochromatosis & $1(0.6)$ \\
\hline & Sickle cell anemia & $1(0.6)$ \\
\hline \multirow{3}{*}{ Transplant due to rejection, $\mathrm{n}(\%)$} & Acute rejection & $3(1.9)$ \\
\hline & Chronic rejection & $3(1.9)$ \\
\hline & Primer non function & $2(1.2)$ \\
\hline Cryptogenic cirrhosis, n (\%) & & $27(16.7)$ \\
\hline Nonalcoholic steatohepatitis, n (\%) & & $21(13.0)$ \\
\hline Alcoholic cirrhosis, n (\%) & & $19(11.7)$ \\
\hline
\end{tabular}


rejection, $1(3.5 \%)$ patient had primary non-function, 1 (3.5\%) patient had delayed graft dysfunction who underwent a second LT (patients with repeat LT history were excluded, please see what you describe above!). Mortality developed in the first year after transplantation in $18(11.1 \%)$, in the second year in 5 (3.1\%), in the third year in $2(1.2 \%)$ patients. One-year survival was $88.9 \%$, two-year survival was $85.8 \%$, and three-year survival was $83.3 \%$. Mortality was linked to sepsis in 14 (48.3\%) patients, pneumonia in $6(20.7 \%)$ patients, acute myocardial infarction (AMI) in $2(6.9 \%)$ patients, primary non-function in 2 (6.9\%) patients, and 1 (3.5\%) patient acute respiratory distress syndrome (ARDS) due to Severe acute respiratory syndrome Coronavirus-2 virus (COVID-19) infection that develops one year after transplantation.

COVID-19 infection was not observed in any patient preoperatively or early after the operation. Seven $(4.3 \%)$ patients were diagnosed with COVID-19 infection at least 4 months after the operation. One $(0.6 \%)$ of these patients died due to ARDS, and the other patients were discharged home (Table 5).

\section{Discussion}

LT is the most effective treatment method in ALF and endstage liver failure. An earlier analysis showed approximately 64000 LTs were performed in Europe from 1988 to 2009, and the most common cause was cirrhosis due to alcoholic liver cirrhosis, HCC, and viral hepatitis (13). The 5-year and 10-year survival were reported as $72 \%$ and $62 \%$, respectively (13). Transplants due to cirrhosis associated with viral hepatitis have also shown a gradual increase (13).

Today, with improved immunosuppressive treatments, surgical techniques, perioperative and intensive care management 1-year survival has exceeded $90 \%$ in more experienced transplantation centers $(10,11,14-16)$. Survival after cadaveric LT was reported as $91.4 \%, 82.5 \%$, and $74.7 \%$ at 1,5 , and 10 years, respectively, by different authors previously

\begin{tabular}{|lcc|}
\hline \multicolumn{3}{|c|}{ Table 3. Underlying etiological diseases of liver transplant patients due to hepatocellular carcinoma } \\
\hline \multirow{2}{*}{ Chronic viral hepatitis, $\mathrm{n}(\%)$} & Hepatitis B virus & $19(44.2)$ \\
\cline { 2 - 3 } & Hepatitis D virus & $2(4.7)$ \\
\cline { 2 - 3 } & Hepatitis C virus & $1(2.3)$ \\
\hline Cryptogenic cirrhosis, $\mathrm{n}(\%)$ & $8(18.6)$ \\
\hline Alcoholic cirrhosis, $\mathrm{n}(\%)$ & & $7(16.3)$ \\
\hline Nonalcoholic steatohepatitis, $\mathrm{n}(\%)$ & $6(14.0)$ \\
\hline
\end{tabular}

\begin{tabular}{|c|c|c|c|}
\hline \multirow{8}{*}{$\begin{array}{l}\text { Perioperative/early postoperative } \\
\text { complications, } \mathrm{n}(\%)\end{array}$} & \multirow{2}{*}{ Arterial complications } & Hepatic artery thrombosis & $4(2.5)$ \\
\hline & & Hepatic artery dissection & $2(1.2)$ \\
\hline & \multirow{2}{*}{ Venous complications } & Portal vein thrombosis & $6(3.7)$ \\
\hline & & Vena cava stenosis & $1(0.6)$ \\
\hline & \multirow{3}{*}{$\begin{array}{l}\text { Bile duct and anastomosis } \\
\text { complications }\end{array}$} & Leakage & $22(13.6)$ \\
\hline & & Stenosis & $20(12.4)$ \\
\hline & & Leakage+stenosis & $8(4.9)$ \\
\hline & Neurological complications & Brachial plexus injury & $1(0.6)$ \\
\hline \multirow{13}{*}{ Postoperative/late complications, n (\%) } & Hepatobiliary bleeding & & $4(2.5)$ \\
\hline & Gastrointestinal system bleeding & & $4(2.5)$ \\
\hline & Intracranial bleeding & & $2(1.2)$ \\
\hline & Bile peritonitis & & $2(1.2)$ \\
\hline & Wound infection & & $1(0.6)$ \\
\hline & Intra-abdominal abscess & & $1(0.6)$ \\
\hline & Incisional hernia & & $1(0.6)$ \\
\hline & Pleural effusion & & $1(0.6)$ \\
\hline & Ileus & & $1(0.6)$ \\
\hline & Colon perforation & & $1(0.6)$ \\
\hline & Duodenal perforation & & $1(0.6)$ \\
\hline & Scrotal Fournier gangrene & & $1(0.6)$ \\
\hline & Acute appendicitis & & $1(0.6)$ \\
\hline
\end{tabular}




\begin{tabular}{|c|c|c|}
\hline \multirow{5}{*}{ Graft losses causing mortality, n (\%) } & Sepsis & $14(48.3)$ \\
\hline & Pneumonia & $6(20.7)$ \\
\hline & Acute myocardial infarction & $2(6.9)$ \\
\hline & Primary non-function & $2(6.9)$ \\
\hline & COVID-19 associated ARDS & $1(3.5)$ \\
\hline \multirow{3}{*}{ Graft losses with retransplantation without mortality, n (\%) } & Chronic rejection & $2(6.9)$ \\
\hline & Primary non-function & $1(3.5)$ \\
\hline & Delayed graft dysfunction & $1(3.5)$ \\
\hline
\end{tabular}

(10). In our study, 1-year survival was $88.9 \%$, 2-year survival was $85.8 \%$, and 3 -year survival was $83.3 \%$, which is close to the literature. In a similar study in Turkey, the mortality rate was $25.5 \%$ during the follow-up period, more than half of mortality occurred in the first 3 months, and approximately $20 \%$ were lost during operation (16). In our study, no mortality developed during the operation, our mortality rate was $15.4 \%$ during the follow-up period.

In the literature, the most common etiological causes of LT are end-stage hepatic failure due to viral hepatitis, alcoholinduced cirrhosis, and HCC (2). Yaprak et al. (16) reported that the most common etiological causes in patients who underwent LT were chronic HBV/HDV, chronic HCV, primary biliary cholangitis/primary sclerosing cholangitis, and cryptogenic cirrhosis, respectively. In our study, the most common etiological causes were consistent with that earlier study.

Postoperative complications are still an important issue in LT recipients. Biliary complications are the most common, having been reported in 5-32\% of recipients (17). Biliary complications are one of the most important causes of chronic graft rejection in the long term (18). Strictures and leaks in the bile ducts or anastomosis area are the most common issues (16-22). Some studies have suggested that the main risk factor is the type of biliary reconstruction, but the complication rate of the Roux-en-Y technique is similar to choledocholedocostomy (23). The ductto-duct anastomosis of the common bile duct has the advantage of easy access to the bile system and preservation of the Oddi sphincter, which prevents reflux to the bile duct (23-25). In the current study, biliary complications were observed in 3 patients (21.4\%) who underwent Roux-en-Y choledocojejunostomy, while $47(31.8 \%)$ patients who underwent canal-to-duct had biliary complications. Pfitzmann et al. (10) reported the rate of postoperative biliary complication rate as $24.3 \%$. Another large study reported $17.8 \%$ biliary complications, and the cumulative incidence after 1, 3, and 5 years after LT was $12.9 \%, 18.2 \%$, and $20.2 \%$, respectively (20). In the current study, the biliary complication rate was $30.9 \%$, and bile duct leakage and stenosis in the biliary tract were the most common, consistent with the literature.
Postoperative vascular complications are frequently reported in the literature. While hepatic artery thrombosis, one of the early surgical complications after transplantation, is observed in $1-7 \%$ of the recipients, it may cause graft dysfunction by $27.4 \%$ within 5 years (26). Among the venous complications, portal vein thrombus has been reported at a rate of $2.1-26 \%$ and inferior vena cava anastomotic stenosis at a rate of $1-6 \%(27,28)$. The arterial complication rate was reported as $11.4 \%$ (10). In a sample from Turkey, hepatic artery thrombus was found in $1 \%$ and portal vein thrombus in $1.5 \%$ of the recipients (16). In the current study, the most common vascular pathologies were portal vein thrombus $(3.70 \%)$ and hepatic artery thrombus $(2.47 \%)$, slightly higher than the previous study. Bacterial pathogens are the most common causes of infection after liver transplantation, the highest incidence occurs during the first month after LT, viral infections are more common after 3 months, and fungal infections are less common following LT (29). At least one case of biopsy-proven acute rejection was reported in 16-27\% of patients who underwent live donor LT (30-35). In our study, acute and chronic rejection was detected in $3(1.8 \%)$ patients after LT, markedly lower than the previous reports.

The incidence of acute and chronic rejection has decreased with the improvement of immunosuppression regimens in LT recipients. Acute cellular rejection occurs in $15-25 \%$ of liver transplant recipients with tacrolimus-based immunosuppression regimens and is usually resolved with steroids in the majority (36). Another major issue after LT is the recurrence of the primary disease. While congenital anatomical diseases do not recur, other causes like HBV and HCV infection, primary biliary cholangitis, primary sclerosing cholangitis, autoimmune hepatitis, hemochromatosis, $\mathrm{NASH}$, alcohol-induced liver disease, and HCC can recur after LT and cause graft loss $(37,38)$. In the current study, primary disease recurrence was roughly $10 \%$ in HCC patients with background HBV.

In a previous study from Turkey, sepsis, pneumonia, and acute renal failure were the main causes of mortality, whereas prolonged biliary complications, HCC recurrence, preoperative death, sepsis, early graft loss, and intraabdominal bleeding were linked to mortality in another country (16). The most common cause of mortality in the current study was sepsis, pneumonia, 
AMI, and primary non-function, showing differences from other international centers.

The limitations of the current study are its retrospective design and single-center involvement. Nonetheless, the large sample size is a strength concerning the previous reports from Turkey.

\section{Conclusion}

This study showed a considerable number of LTs can be made from both living donors and cadavers, and age, gender, underlying diseases, follow-up periods, postoperative complications, and mortality rate were comparable to the studies conducted in Turkey and the world.

\section{Ethics}

Ethics Committee Approval: The study was approved by the Clinical Research Ethics Committee of Istanbul Yeni Yuzyil University (protocol date and number: 13.08.2020/033).

Informed Consent: Retrospective study.

Peer-review: Externally peer-reviewed.

\section{Authorship Contributions}

Concept: A.B., Design: A.B., Data Collection or Processing: A.B., M.S., Analysis or Interpretation: A.B., M.S., Literature Search: A.B., M.S., Writing: A.B.

Conflict of Interest: No conflict of interest was declared by the authors.

Financial Disclosure: The authors declared that this study received no financial support.

\section{References}

1. Starzl TE, Marchioro TL, Porter KA, Brettschneider L. Homotransplantation of the liver. Transplantation. 1967;5:790803.

2. European Association for the Study of the Liver. EASL Clinical Practice Guidelines: Liver transplantation. J Hepatol. 2016;64:433-485.

3. Adam R, Karam V, Delvart V, et al. Evolution of indications and results of liver transplantation in Europe. A report from the European Liver Transplant Registry (ELTR). J Hepatol. 2012;57:675-688.

4. Dutkowski P, De Rougemont O, Müllhaupt B, Clavien PA. Current and future trends in liver transplantation in Europe. Gastroenterology. 2010;138:802-9.e94.

5. Wiesner R, Edwards E, Freeman R, et al. Model for end-stage liver disease (MELD) and allocation of donor livers. Gastroenterology. 2003;124:91-96.

6. Habib S, Berk B, Chang CC, et al. MELD and prediction of post-liver transplantation survival. Liver Transpl. 2006;12:440447.

7. Benten D, Staufer K, Sterneck M. Orthotopic liver transplantation and what to do during follow-up: recommendations for the practitioner. Nat Clin Pract Gastroenterol Hepatol. 2009;6:2336.

8. McGuire BM, Rosenthal P, Brown CC, et al. Long-term management of the liver transplant patient: recommendations for the primary care doctor. Am J Transplant. 2009;9:19882003.

9. Varotti G, Grazi GL, Vetrone G, et al. Causes of early acute graft failure after liver transplantation: analysis of a 17-year single-centre experience. Clin Transplant. 2005;19:492-500.

10. Pfitzmann R, Nüssler NC, Hippler-Benscheidt M, Neuhaus R, Neuhaus P. Long-term results after liver transplantation. Transpl Int. 2008;21:234-246.

11. Busuttil RW, Farmer DG, Yersiz H, et al. Analysis of long-term outcomes of 3200 liver transplantations over two decades: a single-center experience. Ann Surg. 2005;241:905-918.

12. Amador $A$, Charco $R$, Martí $J$, et al. One thousand liver transplants: the hospital clinic experience. Transplant Proc. 2005;37:3916-3918.

13. Strassburg CP, Manns MP. Lebertransplantation: Indikationen und Ergebnisse [Liver transplantation: indications and results]. Internist (Berl). 2009;50:550-560.

14. Busuttil RW, Lake JR. Role of tacrolimus in the evolution of liver transplantation. Transplantation. 2004;77(9 Suppl):S44-S51.

15. Burroughs AK, Sabin CA, Rolles $K$, et al. 3-month and 12-month mortality after first liver transplant in adults in Europe: predictive models for outcome. Lancet. 2006;367:225-232.

16. Yaprak O, Dayangaç M, Demirbaş BT, Güler N, Yüzer Y, Tokat Y. Canlı vericiden sağ lob karaciğer nakli sonuçlarımız. Turkish Journal of Surgery/Ulusal Cerrahi Dergisi. 2011;27:82-85.

17. Ayoub WS, Esquivel CO, Martin P. Biliary complications following liver transplantation. Dig Dis Sci. 2010;55:1540-1546.

18. Sharma S, Gurakar A, Jabbour N. Biliary strictures following liver transplantation: past, present and preventive strategies. Liver Transpl. 2008;14:759-769.

19. Mejía GA, Olarte-Parra C, Pedraza A, Rivera JB, Benavides CA. Biliary Complications After Liver Transplantation: Incidence, Risk Factors and Impact on Patient and Graft Survival. Transplant Proc. 2016;48:665-668.

20. Hwang S, Lee SG, Sung KB, et al. Long-term incidence, risk factors, and management of biliary complications after adult living donor liver transplantation. Liver Transpl. 2006;12:831838.

21. Egawa $\mathrm{H}$, Inomata $\mathrm{Y}$, Uemoto $\mathrm{S}$, et al. Biliary anastomotic complications in 400 living related liver transplantations. World J Surg. 2001;25:1300-1307.

22. Sánchez Cabús S, Calatayud D, García-Roca R, et al. Las complicaciones biliares en el trasplante hepático de donante vivo no afectan los resultados a largo plazo [The biliary complications in live donor liver transplant do not affect the long-term results]. Cir Esp. 2013;91:17-24.

23. Davidson BR, Rai R, Kurzawinski TR, et al. Prospective randomized trial of end-to-end versus side-to-side biliary reconstruction after orthotopic liver transplantation. Br J Surg. 1999;86:447-452. 
24. Park JS, Kim MH, Lee SK, et al. Efficacy of endoscopic and percutaneous treatments for biliary complications after cadaveric and living donor liver transplantation. Gastrointest Endosc. 2003;57:78-85.

25. Sawyer RG, Punch JD. Incidence and management of biliary complications after 291 liver transplants following the introduction of transcystic stenting. Transplantation. 1998;66:1201-1207.

26. Mourad MM, Liossis C, Gunson BK, et al. Etiology and management of hepatic artery thrombosis after adult liver transplantation. Liver Transpl. 2014;20:713-723.

27. Audet M, Piardi T, Panaro F, et al. Four hundred and twentythree consecutive adults piggy-back liver transplantations with the three suprahepatic veins: was the portal systemic shunt required?. J Gastroenterol Hepatol. 2010;25:591-596.

28. Bhangui P, Lim C, Salloum C, et al. Caval inflow to the graft for liver transplantation in patients with diffuse portal vein thrombosis: a 12-year experience. Ann Surg. 2011;254:10081016.

29. Romero FA, Razonable RR. Infections in liver transplant recipients. World J Hepatol. 2011;3:83-92.

30. U.S. Multicenter FK506 Liver Study Group. A comparison of tacrolimus (FK 506) and cyclosporine for immunosuppression in liver transplantation. N Engl J Med. 1994;331:1110-1115.

31. Randomised trial comparing tacrolimus (FK506) and cyclosporin in prevention of liver allograft rejection. European FK506 Multicentre Liver Study Group. Lancet. 1994;344:423428.
32. Neuhaus P, Blumhardt G, Bechstein WO, et al. Comparison of FK506- and cyclosporine-based immunosuppression in primary orthotopic liver transplantation. A single center experience. Transplantation. 1995;59:31-40.

33. Levitsky J, Goldberg D, Smith AR, et al. Acute Rejection Increases Risk of Graft Failure and Death in Recent Liver Transplant Recipients. Clin Gastroenterol Hepatol. 2017;15:584-593.e2.

34. Rodríguez-Perálvarez M, Rico-Juri JM, Tsochatzis E, Burra P, De la Mata M, Lerut J. Biopsy-proven acute cellular rejection as an efficacy endpoint of randomized trials in liver transplantation: a systematic review and critical appraisal. Transpl Int. 2016;29:961-973.

35. Shindoh J, Akamatsu N, Tanaka T, et al. Risk factors for acute liver allograft rejection and their influences on treatment outcomes of rescue therapy in living donor liver transplantation. Clin Transplant. 2016;30:880-885.

36. Choudhary NS, Saigal S, Bansal RK, Saraf N, Gautam D, Soin AS. Acute and Chronic Rejection After Liver Transplantation: What A Clinician Needs to Know. J Clin Exp Hepatol. 2017;7:358-366.

37. Young $\mathrm{K}$, Liu B, Bhuket $\mathrm{T}$, et al. Long-term trends in chronic hepatitis B virus infection associated liver transplantation outcomes in the United States. J Viral Hepat. 2017;24:789796.

38. Cholankeril G, Ahmed A. Alcoholic Liver Disease Replaces Hepatitis C Virus Infection as the Leading Indication for Liver Transplantation in the United States. Clin Gastroenterol Hepatol. 2018;16:1356-1358. 